\title{
Exhibiting Regional LGBTQ History in Dallas, Texas
}

\author{
Jaimi Parker and Morgan Gieringer
}

\section{ABSTRACT}

From 2017 to 2019 archivists and librarians at the University of North Texas Special Collections have worked with community members and city officials to create exhibits featuring archival materials from the LGBTQ Archive. There have been several obstacles to presenting accurate historical interpretation of Dallas LGBTQ community history, including lack of sufficient archival documentation, and differences between archival sources and community members' personal experiences. Grappling with these challenges has allowed UNT Special Collections archivists and librarians to engage community members in a personal, meaningful discussion, and ultimately have led to both successful exhibits as well as strengthened relationships to LGBTQ community members.

\section{ABSTRAKTI}

Vuosina 2017-2019 University of North Texas Special Collectionin arkiston- ja kirjastonhoitajat ovat tehneet yhteistyötä lhbtq-yhteisön ja kaupungin virkailijoiden kanssa rakentaessaan LGBTQ Archivesin kokoelmiin perustuvia näyttelyitä. Historiallisesti tarkan tulkinnan esittämisessä Dallasin Ihbtq-yhteisöstä on ollut monia hankaluuksia, mukaan lukien arkistoinnin puutteellisuus ja arkistolähteiden ja yhteisön kokemusten väliset ristiriidat. Arkiston- ja kirjastonhoitajat ovat käsitelleet haasteita käymällä henkilökohtaisia ja merkityksellisiä keskusteluja Ihbtq-yhteisön kanssa, mikä on johtanut sekä onnistuneisiin näyttelyihin että vahvempaan yhteisösuhteeseen.

\section{Introduction}

University of North Texas Special Collections holds one of the largest LGBTQ archives in the Southwest, and has worked with community partners for years in building and sharing the LGBTQ Archive. For three years, beginning in 2017, Special Collections worked with The Dallas Way, an LGBTQ community archives organization, to create three major exhibits for display at Dallas City Hall during Pride Month. The placement of the exhibits at Dallas City Hall has validated the personal experiences of many community members who have been challenged by homophobia and bigotry throughout their lives, by showing the acceptance of the LGBTQ community by the local government. The creation of these exhibits has been rewarding, but presented several obstacles including representing accurate historical interpretations of Dallas LGBTQ community history by depicting negative aspects of the LGBTQ community, discrepancies between archival sources and community members' personal experiences, and a lack of diverse representation within the LGBTQ Archive. Grappling with these challenges has allowed Special Collections librarians and archivists to engage in meaningful discussion with community members, and expand their understanding of the collections and history of the Dallas LGBTQ community. 


\section{Founding of the LGBT Archive of the University of North Texas Special Collections}

University of North Texas Special Collections initiated a major collection development project to collect and preserve LGBTQ history in 2012 with the acquisition of the Resource Center Collection. At over 600 linear feet of materials, the Resource Center Collection documents social services outreach activities and health services for the LGBTQ community of Dallas. Additionally, the collection includes a wide variety of personal and organizational materials donated to the Resource Center over time. The Resource Center Collection began in the 1960s as Phil Johnson, a local gay activist and archivist dedicated himself to preserving the history of the Dallas gay community as it was unfolding. Phil Johnson was a member of almost every gay organization in Dallas, from the first he helped create in 1965, Circle of Friends, to charity and athletic organizations in the 1990s. He dedicated himself to personally collecting materials to document this history. Along with documentation regarding organizations, Johnson collected ephemera for all types of gay and lesbian organizations and events in north Texas, as well as publications from across the country related to gay and lesbian culture. As the collection grew, the Phil Johnson Historic Archives, as it was now called, were transferred to the Resource Center, a community-based organization originally founded to assist the Dallas gay community during the AIDS crisis in the 1980s. The Resource Center was, and continues to be a major hub of healthcare information for the Dallas LGBTQ community, with the primary mission of improving the lives of LGBTQ people and those affected by HIV/AIDS through health and wellness (Resource Center n.d.).

The Resource Center opened the Phil Johnson Library with this collection in 1995, allowing community members access to view and check out materials like books, periodicals, and VHS tapes. The Resource Center found that caring for such a large collection and making it accessible to the public was too great of an obligation which did not fit into their primary mission of providing health and social services to the LGBTQ community, and so began searching for a new repository for the collection in the early 2010s. Resource Center eventually selected UNT Special Collections to be the new repository for this massive collection after years of relationship building.

Since Special Collections acquired the Resource Center Collection, the LGBTQ Archive has continued to grow with individuals and organizations donating their collections. Additionally, Special Collections formed a partnership with The Dallas Way, a non-profit community archives organization focused on collecting the LGBTQ history of Dallas. The Dallas Way has supported Special Collections by facilitating the acquisition of significant collections, fundraising for digitization efforts and by working closely with archivists to accurately describe LGBTQ collections.

Shortly after acquiring the Resource Center Collection, Special Collections created an exhibit from those materials, highlighting major themes, people, and events in the Dallas LGBTQ Community. This exhibit was on display in the Special Collections Reading Room on the UNT campus and was recreated in a digital surrogate (University of North Texas 2014). The materials utilized for this exhibit were digitized, but the expanse of the Resource Center Collection, over 640 boxes of materials, has made full digitization impossible for the time being.

Over the past eight years, Special Collections has prioritized major efforts to collect, digitize and preserve other LGBTQ collections. In addition to personal papers and organizational records, Special Collections was able to acquire a full run of the Dallas Voice newspaper, a weekly LGBTQ newspaper based in Dallas, founded in 1984 and still in publication today. A grant funded project to digitize the Dallas Voice newspaper was 
completed in 2015. Additionally, Special Collections maintains the digital archive of newspapers published from 2004-present day (Dallas Voice, 2014). As part of Special Collections' agreement with The Dallas Way, all collections contributed to the archive by their organization would be digitized as funding allowed. To date, The Dallas Way has contributed over $\$ 60,000$ in funding. This has led to a dramatic increase in the number of LGBTQ primary sources available on the Portal to Texas History and the UNT Digital Library. As of March 2020, Special Collections has nearly 12,000 LGBTQ items available for view on the Portal to Texas History, with that number ever increasing (The Portal to Texas History n.d.).

The focus on digitizing LGBTQ collections has allowed Special Collections to easily utilize this content for social media posts throughout the year, highlighting milestones and anniversaries. Though Special Collections is part of a larger institution, they have their own Facebook and Twitter accounts managed by staff within the department. These accounts serve not only as a means to share basic information about the department, but are also a key way to communicate new collection acquisitions, digitization milestones, and research opportunities for all collecting areas. While Special Collections utilizes social media platforms to promote all collecting areas, there has been a major push to share the LGBTQ collections, in an effort to both stay connected with the community and to let potential researchers know what types of materials are available in these collections.

In 2017, Special Collections curated an exhibit, Threads of Remembrance, to commemorate the $30^{\text {th }}$ anniversary of the creation of the AIDS Memorial Quilt. Drawn from the archive of the Dallas Metroplex Chapter of the NAMES Project Foundation, the exhibit includes information on Dallas' efforts in displaying and adding to the AIDS Memorial Quilt, as well as photographs of quilt panels that were donated through the organization, honoring local people lost to AIDS and AIDS complications through the early 2000s. This exhibit was displayed in the Special Collections Reading Room on UNT's campus, as well as through an accompanying digital exhibit (University of North Texas 2018).

As UNT Special Collections established a reputation as a responsible steward of LGBTQ historical materials, more collections have been acquired. Being recognized as a good steward is significant for people considering a donation of LGBTQ archives. Since LGBTQ people have traditionally been marginalized, there is prevalent fear among LGBTQ community members that their histories will be marginalized as well. However, frequent engagement with LGBTQ people at events and exhibits has helped to demonstrate the library's dedicated and ongoing interest in preserving LGBTQ history. The LGBTQ Archive has been a valuable tool in many scholarly and journalistic works, as well as a resource for visual artists and filmmakers. UNT Libraries was credited for research assistance in the 2013 film Dallas Buyers Club.

\section{LGBTQ Archival Materials in Pride Month Exhibits}

Though Special Collections is part of a larger institution, and must focus on supporting the needs of students and faculty, they have a wider reach like many similar institutions and must "welcome and serve a broader community of scholars and researchers" (Harris, Weller 2012). The role of outreach activities for special collections departments to share their collections has been proven necessary to accomplish their goals of providing information to researchers, be this outreach through creating accessible finding aids online, digitization of collections, public programming, or other related activities. One strong method for special collections to share their materials with a large audience is by exhibiting those materials. Placing materials on display and including informative 
text about the materials and background story allows viewers to interact with primary source materials, and allows the special collections to take on the role of disseminating knowledge. As Gelfand (2013) describes, exhibits have become increasingly popular in the archives and special collections professions since the end of WWII, as "an essential part of their educational mission, as well as a method of outreach." Exhibits are an easy way to promote the institution and allow archivists to be more proactive in helping researchers to discover collections (Gelfand 2013).

Exhibits form a significant means of outreach to underrepresented communities, both as a method of recognizing and honoring their history, but also as a means to connect with individuals and organizations which may become future donors to the archive. However, collection and exhibition of LGBTQ historical materials by institutions is a sensitive subject and can represent specific challenges to the institution. These challenges may also be amplified significantly based upon geography. In the United States, LGBTQ people and organizations in the South, and outside of major metropolitan areas are more likely to face broad inequalities. So far, no southern US state has passed anti-LGBTQ discrimination bills, and states such as Texas and Tennessee continue to introduce legislation specifically allowing businesses, health care providers and other workers to deny services on the basis of sexual orientation This lack of legal protection leads to overall disparities in social and economic outcomes for LGBTQ people in all communities, but especially in more rural communities where LGBTQ people are isolated and less likely to have support networks in place. The history of inequality in the southern United States is particularly notorious. According to a survey by the Gay and Lesbian Alliance Against Defamation (n.d.), people in the South report discomfort with LGBTQ people at higher levels than people in non-Southern states. The additional burden of being LGBTQ in the South brings with it an additional need for archivists and curators to recognize that "the lived experience of an LGBT-identifying member of a regional community may be significantly different to those in bigger urban settings" (Lymn \& Leah 2017).

The $50^{\text {th }}$ anniversary of the 1969 New York Stonewall Riots was a time of great celebration in many LGBTQ communities across North America. From this point on, it is easy to tell a simplified narrative of LGBTQ history based on an upward trajectory in LGBTQ rights starting in 1969 and continuing forward, in an ever-evolving narrative of positive moments and betterment for the community as a whole. However, individual archival collections reveal a much different and nuanced story which is greatly influenced by gender, race, socio-economic background, culture and religion. Additionally, although the LGBTQ community was marginalized and largely invisible to mainstream culture prior to 1969 , gay, lesbian and transgender people existed prior to that time. For example, in Dallas, the Circle of Friends was founded in 1965 to "to establish and promote communication, understanding and harmony between the homophile community and the general public" (Circle of Friends 1965). Jessie Lymn and Sam Leah (2017) have argued that "there is a dominant narrative of progress" in regional history in particular, and that "regional optimism" is at odds with social histories of communities outside the mainstream culture. For exhibits pertaining to regional queer history, it is important to acknowledge the complex and sometimes negative narratives alongside the positive and progressive narratives which permeate regional historical discourse.

People in the LGBTQ community continue to face harassment, discrimination, and hate crimes. In 2019, the state of Texas ranked number one in the number of murders of transgender people, with over half of those murders occurring in Dallas (McGaughy 2019). It is important to recognize the inequalities and significant danger faced by some members of the LGBTQ community while also celebrating the many accomplishments documented in the archive.

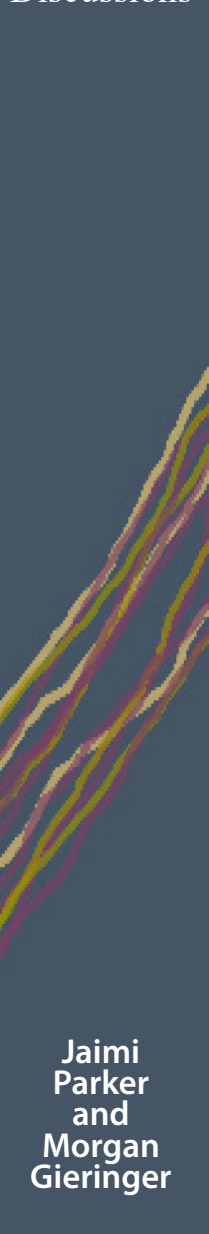


Many people outside of Texas know of Dallas as the site of President John F. Kennedy's assassination, and the resulting nickname given to Dallas: The City of Hate (Siegal 2017). As a stronghold of ultra-conservatism, Dallas historically resisted progressive movements, and it is no surprise that persecution of LGBTQ people has been common. LGBTQ people have faced extreme legal, political and social barriers in Dallas, which is well documented in the archive. The city of Dallas has come a long way in terms of creating policy protecting the LGBTQ community from discrimination, with a score of 100 out of 100 (including bonus points) from the Human Rights Campaign (n.d.) in 2020.

Though Pride Month has been celebrated by the Dallas community for decades, the first Pride Month officially celebrated at Dallas City Hall was in 2012, with the first official proclamation of Pride Month and the unveiling of the Pride Flag in the Dallas City Hall Flag Room (Gerber 2012). This push to celebrate the Dallas LGBTQ community in an official capacity was made by the Dallas LGBT Task Force, led by its founder Dallas Councilwoman (2009-2011) Delia Jasso. D. Travers Scott (2016) describes the important symbolism of the rainbow Pride Flag in showing acceptance of LGBTQ people, as well as the persistence of a community who refuses to be silenced. Scott (2016) goes on to say that this type of representation by the state "connects to, not only, material benefits and protections for certain queer citizens, but also recognizing those citizens as material resources for the state," i.e. generating revenue from Pride events. Having Pride Month officially acknowledged by the City of Dallas and the Pride Flag hung in the flag room is of great significance to the Dallas LGBTQ community.

Dallas City Hall itself is an iconic building designed by I.M. Pei with a large six-acre plaza in front, complete with landscaping, benches, fountains, a reflecting pool, and large sculptures (City of Dallas n.d.). This plaza in front of Dallas City Hall was created to be a public space, inviting the people of the city to come together. Similarly, the interior of Dallas City Hall is a place for the public. People go to City Hall to pay bills, access city services, and attend public meetings including those of the various city councils working to create public policy. The display of LGBTQ artifacts within Dallas City Hall is a symbolic action meant to prominently acknowledge the journey of LGBTQ community members in Dallas. Creating opportunities (through funding or providing space for exhibits) for the LGBTQ community to learn about and celebrate their history is a common theme among cities, states and major corporations who wish to signify their allyship to the queer community.

The exhibit space at Dallas City Hall is located on the first floor on the west side of the building, pictured in Fig. 1. This area has a massive atrium going

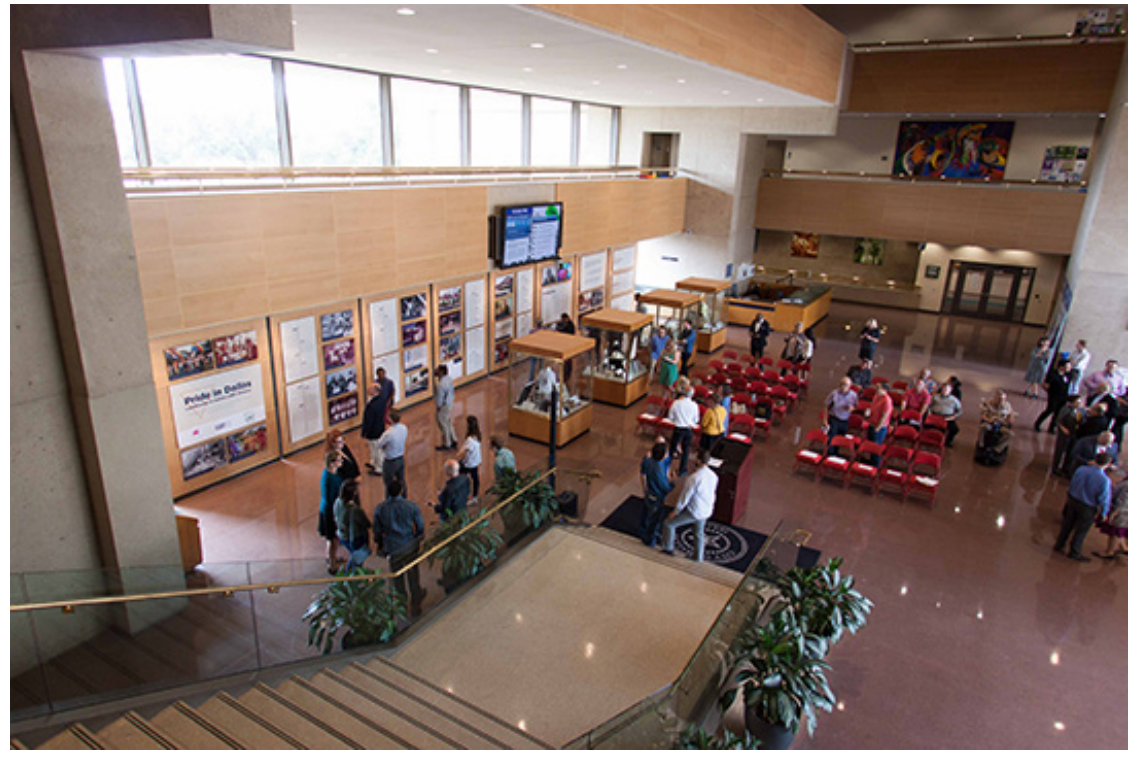

Fig. 1. Dallas City Hall exhibit area and atrium prior to reception for "Pride in Dallas" reception, June 1, 2017. 
up five stories, with walkways around the perimeter of each floor. From the entrance of the building, the exhibit space is directly across the open hall, consisting of four large glass display cases and a row of rotating walls that are nearly 3 meters tall and 16 meters across when the walls are locked in place to create a single long surface.

Each of the exhibits Special Collections created for display at Dallas City Hall during Pride Month were created specifically to fit the exhibit space in this large atrium. The large wall panels for each exhibit were designed to be eye catching so that passersby would be drawn in by the imagery. The cases displayed in front of the wall were filled with original artifacts and reproductions where appropriate, and in each exhibit each case had a large $\mathrm{t}$-shirt or similar article of clothing displayed on a mannequin at the center of the case to help draw people in, as can been seen in Fig. 2 .

\section{Exhibit Site and Themes 2017-2019}

When the initial exhibit, titled Pride in Dallas: Landmarks in Dallas LGBT History, was requested by the LGBT Employee Association of Dallas in 2017, it was meant to be a one-time project to share Dallas LGBTQ history. Special Collections immediately asked The Dallas Way to be a partner on this project for funding and assistance in creating the exhibit text. The idea of creating a timeline to share major milestones in the city's history seemed like the best approach. This would allow for a great overview and some more in-depth information on specific areas of interest. The authors began compiling the timeline information consisting of major events, important people, organization establishments, court cases, etc. After the first draft was created, it was sent to the board members of The Dallas Way to add any major points that were missed and to verify dates and names.
With this initial exhibit, it became obvious that there were not many materials within the LGBTQ Archive that reached into the present day. The LGBT Employee Association of Dallas helped to gather information on major initiatives being focused on in the Dallas LGBTQ community at the time. The topics they chose to represent were LGBTQ youth homelessness and a program founded to address those needs, a recent push to increase safety in Oak Lawn, the historically gay neighborhood of Dallas, after two years of increased violence, and the creation and work of the LGBT Taskforce under the Dallas Mayor's office.

Because of the broad range of topics for this exhibit, and because Special Collections collects artifacts in the LGBTQ Archive, it was easy to find materials to fill the four large exhibit cases. The display contained 62 individual archival items and artifacts as well as 10 reproduction images. Each case had an overall theme, namely organizations, recreation, AIDS, and activism, and each side of each case shared one main story related to that theme.

The request for the second exhibit in 2018 came as a surprise, even though the first was a great success. Because of the time restrictions and other projects happening concurrently, the authors decided to offer a remake of an exhibit that had just been created for the Special Collections Reading Room exhibit space titled Threads of Remembrance. This exhibit was focused on the AIDS Memorial Quilt in Dallas and utilized materials from the Dallas Metroplex Chapter of the NAMES Project Foundation Collection, as well as many other LGBTQ collections held by Special Collections. For Dallas City Hall, the focus of the exhibit was expanded to cover the AIDS crisis in Dallas more broadly, with focuses on community health and fundraising programs, the Dallas Buyer's Club, an organization that imported illegal drugs for HIV/AIDS patients in the late 1980s and early 1990s, and a major court case related to discriminatory hospital 
practices in the treatment of people with AIDS. This exhibit was titled Being Here: A Glimpse into the LGBTQ Movement in Dallas and the Fight Against AIDS.

For the second exhibit, the LGBT Employee Association of Dallas assisted in gathering information about what was currently happening concerning HIV/AIDS in Dallas. They provided a narrative of the populations most affected in Dallas at the time, young African American and Latinx people, as well as information on PrEP to help stop the spread of HIV. With the more narrowed topic for this exhibit there were not enough items to adequately fill all four of the large display cases, so only two display cases were utilized with each side of these cases covering a topic, as in the previous exhibit. The display cases for this exhibit contained 38 archival objects and artifacts.

Realizing through the previous two exhibits that the diversity within the LGBTQ Archive was lacking, it seemed appropriate to represent an underrepresented group in the third exhibit in 2019. The authors selected the theme of women in the Dallas LGBTQ community for this exhibit. It would highlight new collection materials (Lory Masters Collection), bring notice to some less researched areas of the collections, and address issues of discrimination within the LGBTQ community that had not been adequately included in the prior exhibits. When creating this exhibit, it was important to all involved that the recent killings of black trans women in Dallas be addressed in some way. This exhibit was titled Women in the Dallas LGBTQ Community.

Assistance with present day information was provided by members of The Dallas Way in the form of highlighting notable women doing work to further women in the community. Again, with this more narrowed topic, there were not adequate items to fill all four of the display cases provided by Dallas City Hall, so only two cases were utilized. The two cases contained 34 archival objects and artifacts.

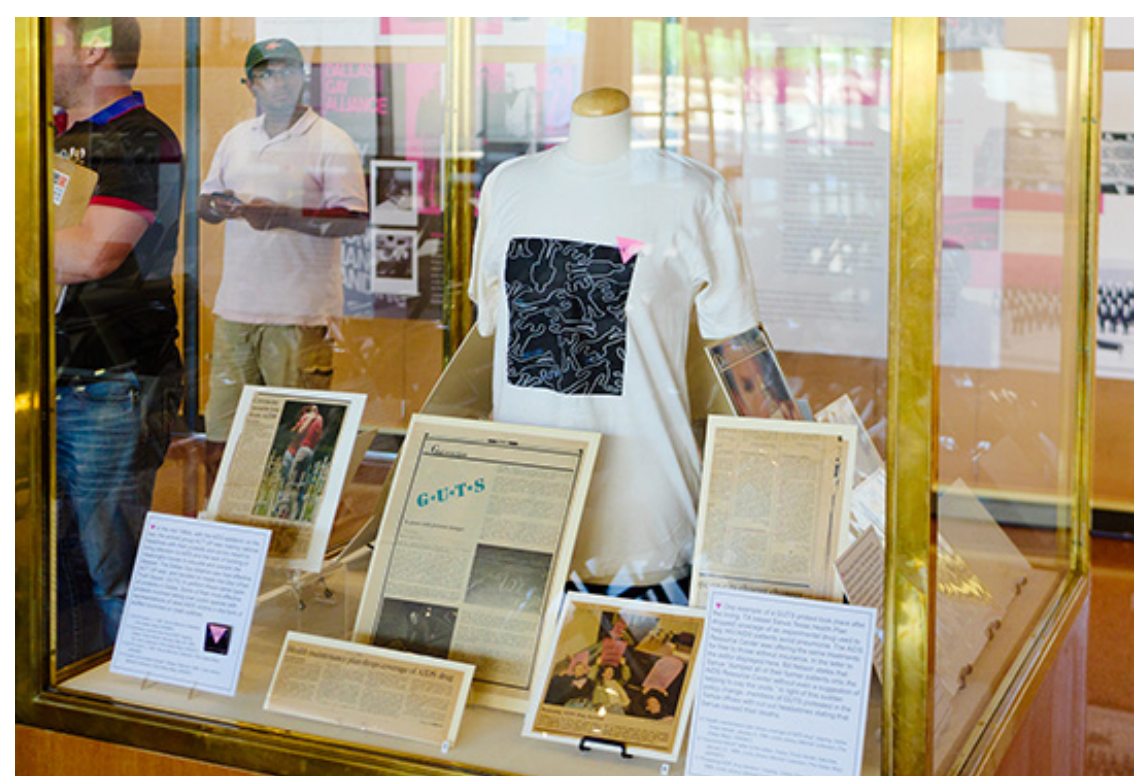

SQS

$1-2 / 2020$

84

Queer Mirror

Discussions

Fig. 2. Case display at Dallas City Hall during "Being Here" exhibit, June 1, 2018.

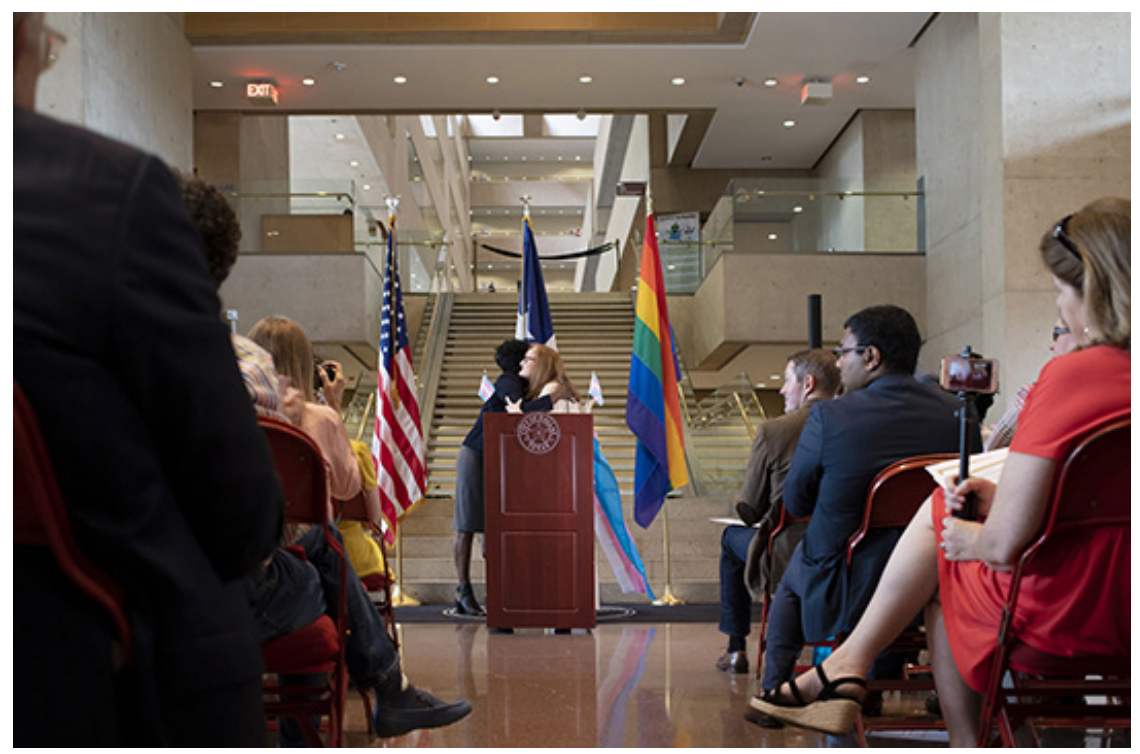

Fig. 3. Shannon Walker speaking during reception for "Women in the LGBTQ Community" exhibit at Dallas City Hall, June 5, 2019. 


\section{Drafting the Texts}

When taking on the first exhibit in 2017, it was clear that the authors, two white heterosexual cis women who did not live through or personally experience the history being represented, could not present this history without input from members of the Dallas LGBTQ community. It was immediately determined that the board members of The Dallas Way should help to create this exhibit. The scope of their involvement was limited to the most critical aspect, drafting the text. It was determined that having too many parties assist in other aspects of the exhibit creation, such as artifact/image selection and design concept, would be too time consuming and unnecessarily difficult. The Dallas Way assisted in drafting the text for each exhibit, while Parker took on the role of artifact/image selection, and both authors worked with members of the UNT Libraries graphic design team to create the wall panel designs for each exhibit. For each exhibit, the text and digitized materials for the wall panels had to be compiled first so that the UNT Libraries graphic designers had adequate time to create the designs and ensure they were printed before the exhibit installation deadline.

For the first exhibit in 2017, the authors began compiling the timeline text with information that was previously utilized in an exhibit on the Resource Center Collection. Additional relevant information had also been gleaned over the years from visiting researchers. The LGBTQ Archive is heavily requested by researchers studying various aspects of LGBTQ history and culture for academic and creative projects, including recent research requests focused on conversion therapy and religion in the LGBTQ community and anti-sodomy laws in Texas. Researchers often spend multiple days, if not weeks, looking through collection materials in the reading room, and employees often take these opportunities to discuss their research and discoveries within the collections with each researcher.
Special Collections also offers Research Fellowships, with part of the stipulation of funding being a final presentation on what the researcher found in the collections and how they plan to incorporate that information into their greater research project. Once the basic timeline was created, spanning 1967 through 2007, the document was shared with The Dallas Way board members for their input and corrections.

Working with The Dallas Way to create the exhibit text for these exhibits was rewarding but presented a few challenges and conflicting ideas that needed to be worked through. One of the major issues that The Dallas Way board members brought up in editing the first exhibit text was the use of the acronym LGBT. In the first draft of the text for this exhibit, this acronym was used throughout, but The Dallas Way suggested that it was inappropriate to use in situations where bisexuals and transgender people were not included and to represent time periods where the term lesbian was not widely used. For example, when talking about the first gay/ally organization founded in Dallas in 1965, the Circle of Friends, The Dallas Way specifically wanted to refer to this as a gay group because the term lesbian was not widely used until the 1980s and this group was specifically for homosexual men and women. This desire to show a more accurate representation of the members of the LGBTQ community that were actually included in these specific historical moments seemed like such an obvious need in writing this narrative, but the authors came of age after the acceptance and widespread use of the LGBT acronym and did not consider this in the first draft.

The Dallas Way were also particular when using the acronym, that it should read GLBT instead of LGBT. Until 2019, The Dallas Way utilized the qualifier "a GLBT history project" when they switched the acronym to LGBTQ. The requested changes from LGBT to GLBT did not seem like a battle worth having at the time, though the authors were aware that this

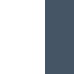


was a signifier of the pervasive sexism that has been prevalent throughout the history of the Dallas LGBTQ community. In hindsight, the authors should have insisted on leaving the acronym as it is generally accepted, with lesbians being represented first, but the requested changes were approved. The Dallas Way also requested that the name of the National March on Washington for Lesbian and Gay Equal Rights have the words lesbian and gay swapped to read National March on Washington for Gay and Lesbian Equal Rights. Because this was a matter of a historically documented title of a major event, for which a flyer was to be displayed, there was not even discussion from the Special Collections team that this change could not be made. The title of the event in the written text of the exhibit would reflect what was on the archival documents in the collection and on display. Another similar request from The Dallas Way was the removal of the apostrophe from Dallas Buyer's Club. Though the apostrophe is not grammatically correct, it is included on archival materials produced by the Dallas Buyer's Club, such as their NEW Source newsletter and product lists. Because the official name of the organization included the apostrophe, and it is well documented as the standard in their original documents which would be on display in the exhibits, that requested change was also not made.

Some of the most helpful feedback offered by The Dallas Way revolved around how to address certain issues or appropriate phrasing. A notable example was in the second exhibit covering the AIDS crisis, where there was a section focused on a famous local drag queen from the 1980s and 90s named Patti Le Plae Safe, whose act focused on sharing information about safe sex practices. When referring to the man playing Patti, the author's original text read "As himself." The Dallas Way corrected this to read "Out of drag." What seemed like a minor adjustment, made a huge difference in showing an understanding and acceptance of drag culture.

\section{Material Selection and Exhibit Design}

In selecting archival materials for display in each of these exhibits, it was important to create a visually interesting display to draw in viewers. As Vassari $(2018,97)$ describes, a display highlighting the different formats of archival materials in a collection "allows for an enriched narrative to be told." The LGBTQ Archive is much more varied in content compared to many archival collections, which often consist mostly of paper materials such as documents, correspondence, and photographs. The LGBTQ Archive contains paper materials as well as artifacts, including t-shirts, stuffed animals, awards, buttons, and all manner of materials that relate to LGBTQ history in Dallas. Utilizing these types of artifacts makes the history come alive. Viewers can imagine members of Team Dallas wearing their uniforms with white Stetson hats to the 1994 Gay Games. The handmade binder with information on creating AIDS Memorial Quilt panels, with pages of various fabrics showing decoration ideas, shows the personal touch of those locals attempting to help the people of Dallas honor their lost loved ones. These three-dimensional objects that relate to everyday life, make the history being told more tangible for viewers.

Documents and photographs were utilized in display cases for each exhibit, alongside artifacts. Because so much of history is captured through writing, documents can help to symbolize events and individuals, or add further context that artifacts cannot (Aubitz, Stern 1990). A few examples of important documents that were utilized in the exhibits are a Gay Games ticket, an "AIDS and Deafness" pamphlet, Dallas Buyer's Club newsletters, handwritten notes from the head writer for the Dallas Voice newspaper, and many covers of the Dallas Voice newspaper showing striking images related to the topic being presented. Each of these items added to the story represented in the case and gave a little more context without adding more narrative text. The ticket for
SQS

$1-2 / 2020$

\section{6}

Queer Mirror Discussions
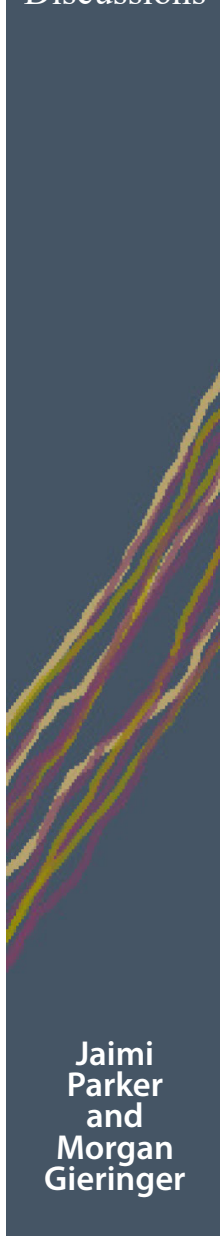
the inaugural Gay Games in 1982 tells a larger story than just the event information. The ticket shows the original title of the event as the Gay Olympic Games, with the word Olympic crossed out with a single narrow line. This piece of ephemera visually helps to tell the story of a lawsuit being filed only weeks before the event, by the International Olympic Committee, forcing the Gay Games to change names (Blackwell 2001). The Dallas Buyer's Club newsletter was a wonderful addition to the AIDS related exhibit, because of its notoriety after the release of the 2013 film of the same name, sans apostrophe. Sharing this history in a more historically accurate context, showing images of the real Ron Woodroof (founder of the Dallas Buyer's Club), and showing viewers that physical materials from this organization still exist, adds legitimacy and realness to the story they might already know. The use of Dallas Voice newspaper covers benefited these exhibits in two ways, first by taking up a large portion of visual space in the cases with interesting graphic materials, and second by showing that the issues that were discussed in the exhibit were issues that the LGBTQ community of Dallas had been discussing while they were occurring.

The wall panels for each exhibit were a major factor in terms of being able to attract visitors of Dallas City Hall to the exhibit space and to tell the bulk of the information being presented. A great deal of thought and time went into the design and image selection for each exhibit, with the authors working closely with graphic designers at UNT Libraries.

The design for the wall panels of the first exhibit in 2017 utilized a clean basic design for the timeline panels so that they could be easily read. Large images from the collections, consisting mostly of original unedited photographs were positioned next to the timeline text to represent some of those major events. It was decided that the images used for the timeline would simply be enlarged, but would not be edited in any other way, allowing viewers to have an accurate representation of the history being presented, and the types of materials in the LGBTQ Archive.
When selecting color options for the wall panels, the idea of going with the obvious rainbow theme was thrown around at first, but it was quickly agreed that too bright and colorful of a design concept would wash out the wonderful photographs from the 1980s and 1990s with that typical sepia hue. The graphic designer chose to focus on a color palette that would complement the images without being overwhelming, and so a simple light tan background color was chosen, with orange and blue as accent colors.

When discussing the design for the AIDS exhibit in 2018, the obvious main color option was red, as it is the color for AIDS awareness, but it also seemed stark and unwelcoming. The graphic designer chose to bring in the main color of The Dallas Way branding, hot pink, and contrasted it with black and white throughout the design to create an eye-catching display. The designer put a great deal of focus in having the graphic design help to tell the story of the pain and loss associated with the AIDS crisis, by utilizing empty black backgrounds on panels describing the early outbreak, fear, and uncertainty that spread through the community. For this exhibit, the graphic designer wanted to incorporate imagery from the collections more fluidly into the graphic design, as opposed to the previous exhibit where each image stood alone. For this exhibit, the graphic designer pulled imagery from the collections, changed their colors to fit into the threecolor design, and photoshopped them into the overall design to create a stunning visual narrative to go along with the text.

When selecting the color palette for the 2019 Women exhibit, early ideas focused on colors often gendered as "feminine" in the United States. Lavender was an early first choice, as it could be seen as a reference to the Lavender Scare, a period in American history where the federal government searched out and fired more than 5,000 homosexual federal government employees between the late 1940s and 1960s (Adkins 2016). Because lavender alone did not seem like a striking enough color to draw in viewers, the designer went with a selection of pastel colors in purples, pinks and 
blues offset with bolder teals and reds. For this design, images from the collections were inserted into the designs with minor editing, like cropping.

\section{Negative Representations}

One major area of disagreement between Special Collections and The Dallas Way came up in the editing of the 2019 exhibit, Women in the LGBTQ Community. Special Collections wrote some general language about the sexism and racism prevalent in the Dallas LGBTQ community, specifically in the 1970 s and 80 s. Special Collections' LGBTQ Archive contains a recently recorded oral history from a prominent lesbian couple, in which they share their experiences with sexism in the LGBTQ community. These issues have been well documented in various formats, including in the documentary Finding Our Voice (2000), created by the local Dallas Public Broadcasting Service station KERA, where women and people of color discuss the various ways that they were denied access to local bars because of sexism and racism. When creating this exhibit, Special Collections and The Dallas Way President, a woman at the time, agreed that sharing this struggle and theme of sexism within the LGBTQ community was important, as it was such a defining factor in how women navigated their place within the community. And, as in the greater American cultural landscape, sexism is still prevalent in even small encounters, such as was witnessed by the authors, with past members of The Dallas Way requesting men be represented first in the acronym (GLBT) used in the first exhibit, instead of sticking with the generally accepted acronym representing women first (LGBT). To represent these general inequalities and sexism within the community, the authors included the following paragraph in the original draft of the exhibit text:

Women often found themselves invisible compared to the larger gay community and were sometimes purposely excluded. Early gay bars would discriminate against lesbians by prohibiting women wearing jeans, or not allowing open toed shoes. Other forms of discrimination were used to target women and people of color at these bars, such as requiring multiple forms of ID to enter.

One of the male board members of The Dallas Way objected to this general representation of white men within the Dallas LGBTQ community, and asked that the language be removed all together, or that a "not all men" type of statement be added to the text. Considering the various discriminatory issues that were to be addressed in the exhibit, as well as their broad representation throughout the LGBTQArchive, there was no way to justify removing this part of the text because of one man's objection. It also seemed inappropriate to add a statement that not all men were like this, which might not come across well in the current social justice era. The compromise was to add a line about the Dallas Gay Alliance's Social Justice Committee eventually shutting down discriminatory practices related to keeping women and people of color out of gathering spaces like bars and clubs.

This exhibit also discussed issues of women's groups excluding other women based on sexual orientation or gender-identity, and women of color feeling underrepresented and creating their own organizations based on cultural background. It was important to not only say that men in the community were against women, but to also represent the breakdowns within this already twice-marginalized group. For instance, Umoja Hermanas (Sisters United), an organization for lesbian women of color founded in 1992, did not initially allow bisexual women to join, until there was a call to action by bisexual women in the community.

These types of discrimination within the LGBTQ community have always been prevalent, and often follow the lines of greater societal prejudices. As the authors began creating these exhibits, the issue of representing the 
wide swath of diversity in the community was important, but as exhibit creation continued, the idea of representing these internal rifts became just as important to sharing history accurately. As future exhibits are created, these types of issues will continue to be addressed so that a clear understanding of this history can be presented, and so that members from all aspects of the community can feel that their experiences are being fairly represented.

\section{Lack of Diversity}

The main issue revealed during the creation of each of these exhibits was the lack of diversity within the LGBTQ Archive. Three main issues that Maxine Wolfe (1998) describes in creating the Lesbian Herstory Archives apply to all minority groups in the LGBTQ population: they have historically been afraid to be publicly visible as a member of the LGBTQ community, they have historically been oppressed and believe their stories are not important, and they do not trust major institutions with their history. Each of these issues create a barrier in collecting and preserving more diverse historical materials from the LGBTQ community. With each exhibit, a point was made to include information about often excluded groups or individuals--women and people of color, for example--, even if representative materials were not present in the LGBTQ Archive. It was important to share what history was known, so that complete subsections of the LGBTQ community were not left out of an exhibit about them. With each exhibit, it became more and more clear that there was much work to be done in collecting and representing the history of this diverse community. The first steps in that process were to acknowledge the issue, and put in effort to represent as many diverse experiences as possible without archival materials, instead of simply saying the history does not exist. As an effort to remind people of the need for more diverse voices in the LGBTQ Archive, members of both Special Collections and The Dallas Way mentioned, in their speeches at the reception events for these exhibits, the need for community members to preserve their own history, and the willingness for each organization to help in that effort.

Much of the information gathered on diverse groups and individuals not represented in the LGBTQ Archive was pulled from the Dallas Voice. Many women's organizations and organizations for people of color were listed within the calendar sections of the Dallas Voice, such as Men of All Colors Together and Dragonflies of Dallas, while others had stories written about them like the Flying W Motorcycle Club, Dallas' first lesbian motorcycle group founded in 1975. In some instances, present day representation of minority groups was needed, such as information about transgender women and the work being done for their rights in the Women in the LGBTQ Community exhibit. Some information on transgender women was gathered from the Dallas Voice, but additional information was gathered and supplied by The Dallas Way, including some documents and images to be used for display in the exhibit.

Though Special Collections was previously aware of the general lack of diversity within the LGBTQ Archive, the creation of these exhibits highlighted the vast absence of women, people of color and transgender people. Though it is not encouraging to realize these gaps, coming to these realizations has allowed Special Collections and The Dallas Way to begin developing plans to correct the issue. The Dallas Way has diversified its board in recent years, and these new younger members represent people of color and transgender people, and they are excited about tapping into their communities to find and preserve these areas of history that are not currently being collected. There are still other sections of the LGBTQ community that have not been reached, including the queer Spanish-speaking 
community and LGBTQ people living in suburban or rural areas outside of Dallas. Special Collections has begun efforts to "Document the Now" as another strategy to create a more inclusive LGBTQ archive, and web archives have become an increasingly important way to document and preserve diverse community histories.

\section{Programs and Reception}

For the initial exhibit in 2017, the LGBT Employee Association of Dallas and The Dallas Way worked together to plan a one-hour reception on June 1, that included short speeches from Dallas LGBTQ City leaders and allies, including two individuals that were mentioned in the exhibit, Judge Barbara Rosenburg and former Dallas City Councilman Chris Luna. The speaker for Special Collections shared the importance of creating this exhibit, and explained that it is a representation of what is available in the LGBTQ Archive, and if any attendee did not see their experiences represented, then they needed to ensure that their history be saved, and Special Collections was there to help. This event also included the annual Pride Flag unveiling. Members from each of the groups involved in putting this exhibit and program together were asked to help unfurl the flag on the second-floor walkway, so that it could hang above the exhibit for the full month of June. Attendance for this inaugural exhibit reception was around 60 individuals with many people from the LGBTQ community attending. As attendees viewed the exhibit many commented that they remembered the events and the people in photos that they hadn't seen in so long. They were excited to have been a part of this history being represented in Dallas City Hall.

The second exhibit reception in 2018 took on a more somber tone, because of the more serious theme of the exhibit. The Dallas LGBT Employee Association and The Dallas Way again worked together to bring in speakers to talk about their experiences during the AIDS crisis in Dallas, with one speaker in particular leaving many in tears after sharing his personal experience battling HIV, the loss of his vision to the disease, and the loss of so many of his friends and loved ones along the way. Again, the speaker representing Special Collections explained to those present that if their experiences were not represented in the exhibit, then they need to take care to document and save that portion of history. Dallas Voice TV recorded the full program, which is available to view on their website (Dallas Voice 2018). Attendance at this reception increased from the previous year, with around 75 people. Again, the Pride Flag was unveiled above the exhibit to hang for the month of June.

For the third exhibit reception in 2019, Dallas Mayor Pro Tem Adam Medrano asked to incorporate the annual Pride Month proclamation and annual awards ceremony celebrating work being done in the Dallas LGBTQ community. The combination of these two events allowed for an increased attendance for both events, with about 150 individuals present. The event began with a moment of silence to honor the four black trans women that had recently been murdered in Dallas and ended with a speech by Dallas transgender rights advocate Shannon Walker (Fig. 3), who was represented in the exhibit.

\section{Positive Outcomes}

The work put into these exhibits has been completely worth the wonderful response and the benefits to the LGBTQ Archive and in developing relationships with the LGBTQ community. Though there were some challenges throughout the process of creating these exhibits, there is clearly a strong desire from the Dallas LGBTQ community to share their history with others and to support the efforts of Special Collections and The Dallas Way in preserving that history. 
Through the creation of these exhibits, the authors have learned a great deal about Dallas LGBTQ history, as well as more detailed information about what is in the LGBTQ Archive. With such a vast array of materials, it is difficult to be familiar with the entire collection, but as Michael $\mathrm{L}$. Taylor (2018) describes in his article "Special Collections Exhibitions: How They Pay Dividends for your Library," one of the major benefits of creating exhibits is that it allows the creators to gain a greater familiarity with the collections, which in turn has allows them to offer greater assistance in helping researchers of collections find the types of materials they are looking for. This has been true for the authors, as their work in researching and selecting display materials for the exhibits has allowed them to discover new and interesting materials in the collections, which could be pointed out to researchers hoping to find specific information within the collections on multiple occasions.

The idea of learning history through the creation of exhibits is one that has been of interest to Special Collections for a while now. There are clear benefits to having people develop a narrative from primary sources, and this type of project could be a good way to connect with students, faculty and community members. Special Collections has helped to implement two class projects around the creation of an exhibit utilizing collection materials, though they did not utilize the LGBTQArchive. These projects utilized smaller collections with a much narrower scope, which seemed to work well for the classes of about fifteen students. If the scope of the exhibit and research was narrow enough, a similar exhibit creation project based on the LGBTQ Archive could be a worthwhile undertaking in helping to teach this history and share it with an audience. Special Collections has taken on similar projects with community members, and have found myriad complications, with one guest-curator of an exhibit abandoning the project with no notice, and refusing to respond to communications, leaving the authors to pick up the pieces. This is not to say that the authors would not entertain the idea of a community-based exhibit project if the right situation presented itself.

Taylor (2018) notes that another major benefit of creating exhibits with archival materials is the creation and strengthening of relationships with community members and donors. This has been true with regards to the Dallas City Hall Pride Month exhibits as they have been a wonderful tool in creating connections within the Dallas LGBTQ community. The first new connection Special Collections made was with the group that initially reached out about creating these exhibits, the LGBT Employee Association of Dallas. After working with them on the first exhibit, there was no question about continuing to work with them to create additional exhibits, as they were a wonderful partner. Through them, Special Collections has also received numerous requests for information regarding the LGBTQ Archive, for displays, and information on happenings in the community.

Special Collections' relationship with The Dallas Way has strengthened during these collaborations. Everyone from The Dallas Way has been enthusiastic about the opportunity to share their collections with the public. Previously this relationship was based primarily on bringing in new collections and creating project plans to have materials digitized. Getting the opportunity to truly create something from scratch together has given all involved a sense of accomplishment and visibility.

During the receptions for each of these exhibits, members of Special Collections met various individuals that have chosen to support the LGBTQ Archive by donating collection materials. Since the first exhibit display in 2017, eight new collections have been donated to the LGBTQ Archive through The Dallas Way including 22 oral history recordings. Accretions have been added to another four collections originally facilitated by The Dallas Way. Special Collections has 
brought in an additional six collections independently and one accretion to an existing collection. Special Collections and The Dallas Way continue to build relationships with potential donors, and emphasize the fact that these materials may be utilized by researchers around the world, and will be used to showcase local history through exhibits like those displayed at Dallas City Hall.

Some new relationships have come out of requests for reuse of the exhibits. Many of these requests have come to Special Collections via the LGBT Employee Association of Dallas or The Dallas Way, as these two entities are more well known within the Dallas LGBTQ community.

The first request for reuse of the 2017 timeline exhibit was for the 30-year anniversary holiday party of the Dallas chapter of the Human Rights Campaign Federal Club. It was exciting to be able to give this exhibit a longer life after its display at Dallas City Hall, so there was no question of taking on this opportunity. The party took place in two large ballrooms on either side of a large atrium on the $40^{\text {th }}$ floor of a building in downtown Dallas. Members of the Federal Club had movable walls that the Special Collections team set up in the atrium to display most of the wall panels, and a small display of artifacts was included, set up in two table-top display cases. About 200 guests attended the party and had the opportunity to view the display.

Employees at the Dallas Public Library Archives saw the 2017 exhibit when it was on display at Dallas City Hall and requested some archival materials to create visual interest for a display in their space for Pride Month 2018. The wall panels were suggested, but their space could not accommodate the size, so they opted for the three-dimensional objects instead. For this request, Special Collections provided a selection of materials used in the original display, along with the text of the exhibit that the Dallas Public Library Archives could use as needed.
There was even a request to reuse the AIDS related exhibit, which was a surprise because of its very specific and somber theme. The organization that requested it was the Dallas chapter of The Red Door Foundation, an HIV/AIDS awareness and prevention non-profit. The organization throws a large fundraising party each year, and the people requesting the exhibit mentioned that they wanted to help bring people's attention back to the roots of the organization and the party by sharing the history of the disease and all the work that had been done in Dallas to help during the crisis

In 2019, the Oak Lawn Branch of the Dallas Public Library requested the panels of the 2017 timeline exhibit be displayed in their library for Pride Month. Oak Lawn is the Dallas gay neighborhood, and their library holds major collections of LGBTQ literature for their patrons to use. This was a great opportunity to have our exhibit available to a wide-ranging audience for an extended period. The library has a gallery rail system along many of the walls in the library, but because of a lack of hardware associated with this gallery rail system, only a portion of the exhibit could be installed. The timeline portion of the display was the main focus, in order to share the most information possible. The timeline was accompanied by a few images, with a few additional images hanging alone around the library where there was less vertical space available.

During this same time, The Dallas Way requested the use of the 2017 timeline exhibit panels for display at the 2019 Dallas Pride Parade at Fair Park. Because of the number of requests for this exhibit, Special Collections decided to reprint the panels so that multiple organizations could use it at once. Because 2019 was the $50^{\text {th }}$ anniversary of the New York City Stonewall Riots, the Dallas Pride Parade was held in June for the first time in its existence, and it was partially televised live. The Dallas Way and the exhibit were part of that live broadcasting.

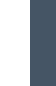


More requests for Pride Month displays have come into Special Collections than can be accommodated, since 2017. The size of the wall panels printed for the Dallas City Hall displays, however, has proven to be a problem. Since this exhibit was specifically created to fit the expansive wall space at Dallas City Hall, despite the panels being modular, many spaces cannot accommodate their size. For these instances, Special Collections created a set of shareable files including the text documents and highresolution images used in the Dallas City Hall exhibits for organizations to create a display that works for their space.

\section{Conclusion}

The LGBTQ Archive at the University of North Texas is an important resource for teaching and research, however, it is also an equally important resource of community memory for the Dallas LGBTQ community. Exhibits have played a crucial role in the development of the LGBTQ Archive by providing a way for a non-scholarly audience to engage with these historical materials. The location of the exhibits at Dallas City Hall has been a symbolic victory for many LGBTQ people who felt politically disenfranchised within the city for many years. Archivists and curators working on these exhibits were sensitive to the many special considerations that LGBTQ history present, such as addressing the great strides of LGBTQ rights activists, while also addressing discrimination within the LGBTQ community itself. Although the exhibits draw from extensive archives of people and organizations, the curators also faced stark absences of women, people of color and transgender individuals. The continued demand for Pride Month exhibits, both at Dallas City Hall and from other local organizations and institutions, indicates that there are many in the community who are eager to create opportunities for education and engagement with LGBTQhistory. Additionally, the archive has benefited greatly from the positive publicity and personal connections made through the exhibits, and so Special Collections will continue to provide archival LGBTQ history displays to satisfy the demand.

\section{Bibliography}

Adkins, Judith. 2016. "These People Are Frightened to Death: Congressional Investigations and the Lavender Scare." Prologue Magazine 48, no. 2 (Summer). https://www.archives.gov/publications/prologue/2016/ summer/lavender.html.

Aubitz, Shawn and Gail F. Stern. 1990. "Developing Archival Exhibitions.” MidAtlantic Regional Archives Conference, Technical Leaflet Series no. 5. https://www.marac.info/assets/documents/marac_technical_leaflet_5.pdf.

Blackwell, Savannah. 2001. "Crushing the Gay Olympics: The USOC's homophobic past." San Francisco Bay Guardian, September 5, 2001. https://web.archive.org/web/20060527003250/http://www.sfbg.com/ News/35/49/49olysb2.html.

Circle of Friends. 1965. Circle of Friends: Constitution and By-Laws. c. 19651974. From University of North Texas Libraries, The Portal to Texas History. https://texashistory.unt.edu/ark:/67531/metadc304801/.

City of Dallas. n.d. "History of Dallas City Hall Buildings." Accessed March 24, 2020. https://dallascityhall.com/government/citysecretary/archives/ Pages/Archives_buildings.aspx.

Dallas Voice. 2018. "DVtv News: Opening remarks on Pride Month exhibit at Dallas City Hall.” Dallas Voice, June 7, 2018. https://dallasvoice.com/ dvtv-news-opening-remarks-on-pride-month-exhibit-at-dallas-city-hall/.

Dallas Voice. 2014. "UNT receives grant to digitize 16 years of Dallas Voice." Dallas Voice, August 24, 2014. https://dallasvoice.com/untreceives-grant-digitize-16-years-dallas-voice/.

Erbentraut, Joseph. 2011. "Chicago History Museum unveils LGBT exhibit.” Windy City Times, May 25, 2011.

Gay and Lesbian Alliance Against Defamation. n.d. "LGBT Life in the South." Accessed February 19, 2020. https://www.glaad.org/southernstories/life.
Queer Mirror

Discussions

Discussions 
Gelfand, Aleksandr. 2013. "If We Build It (and Promote It) They Will Come: History of Analog and Digital Exhibits in Archival Repositories." Journal of Archival Organization 11, no. 1-2: 49-82. https://doi.org/10.1080/153 32748.2013.882160.

Gerber, Pam. 2012 "Dallas has a lot to be proud of." Dallas Voice, June 8, 2012. https://texashistory.unt.edu/ark:/67531/metapth308870/m1/16/.

Harris, Valerie A. and Ann C. Weller. 2012. "Use of Special Collections as an Opportunity for Outreach in the Academic Library." Journal of Library Administration 52, no. 3-4 (Spring): 294-303. https://doi.org/10.1080/0 1930826.2012.684508.

Human Rights Campaign. n.d. "Municipal Equality Index: Dallas, Texas." Accessed April 17, 2020. https://www.hrc.org/mei/search/texas/dallas.

Lymn, Jessie and Sam Leah. 2017. "What Makes an object queer? Collecting and exhibiting LGBT stories in regional museums and archives." Proceedings of RAILS - Research Applications, Information and Library Studies 22, no. 4. (December): 6-8. http://informationr.net/ir/22-4/rails/rails1616. html.

McGaughy, Lauren. 2019. "Texas leads the nation in transgender murders After the latest attack, the Dallas trans community asks why." Dallas Morning News, September 30, 2019. https://www.dallasnews.com/ news/2019/09/30/texas-leads-nation-transgender-murders-accordingnational-lgbtq-organization/.

The Portal to Texas History. n.d. "UNT Libraries Special Collections: Statistics LGBT Collections.” Accessed April 8, 2020. https://texashistory.unt.edu/ explore/collections/lgbt/stats/.

Resource Center. n.d. "Mission and Vision.” Accessed May 5, 2020. https://www. myresourcecenter.org/who-we-are/mission-and-vision.

Scott, D. Travers. 2016. "Reconciling Hall with discourse, written in the shadows of "Confederate" and Rainbow Flags." Critical Studies in Media Communication 33, no. 5: 424-437. https://doi.org/10.1080/15295036.20 16.1224909.

Siegal, Rachel. 2017. "JFK in the 'City of Hate': How Dallas earned its ugly label before the assassination." The Washington Post, November 22, 2017. https://www.washingtonpost.com/news/retropolis/wp/2017/11/22/ jfk-in-the-city-of-hate-how-dallas-earned-its-ugly-label-before-theassassination/.

Taylor, Michael L. 2018. "Special Collections Exhibitions: How They Pay Dividends for Your Library." RBM: A Journal of Rare Books, Manuscripts, and Cultural Heritage 19, no. 2 (November): 121-132. https://doi. org/10.5860/rbm.19.2.121.

University of North Texas. 2014. "The Resource Center LGBT Collection: 50 Years of LGBT History." University Libraries Exhibits. Last modified August 19, 2014. https://exhibits.library.unt.edu/resource-center-exhibit.

University of North Texas. 2018. "Threads of Remembrance." University Libraries Exhibits. Last modified March 8, 2018. https://exhibits.library. unt.edu/aids-quilt.

Vassari, Marissa. 2018. "Voila!: The Rockefeller Archives Center's Exhibit Creation Process." Collections: A Journal for Museum and Archives Professionals 14, no. 1. (March): 95-106. https://doi.org/10.1177/15501 9061801400105.

Vinson, Kay, writer/dir. 2000. Finding Our Voice: The Dallas Gay \& Lesbian Community. Dallas, TX: KERA/KDTN North Texas Public Broadcasting. https://www.kera.org/tv/productions/finding-our-voice-the-dallas-gaylesbian-community/.

Wolfe, Maxine. 1998. "The Lesbian Herstory Archives." S. A. Archives Journal 40: 20-22. http://libproxy.library.unt.edu:2066/login.aspxdirect= true $\& \mathrm{db}=\mathrm{a} 9 \mathrm{~h} \& \mathrm{AN}=2721429 \&$ scope $=$ site.
SQS

$1-2 / 2020$

Queer Mirror

Discussions

Discussions . 